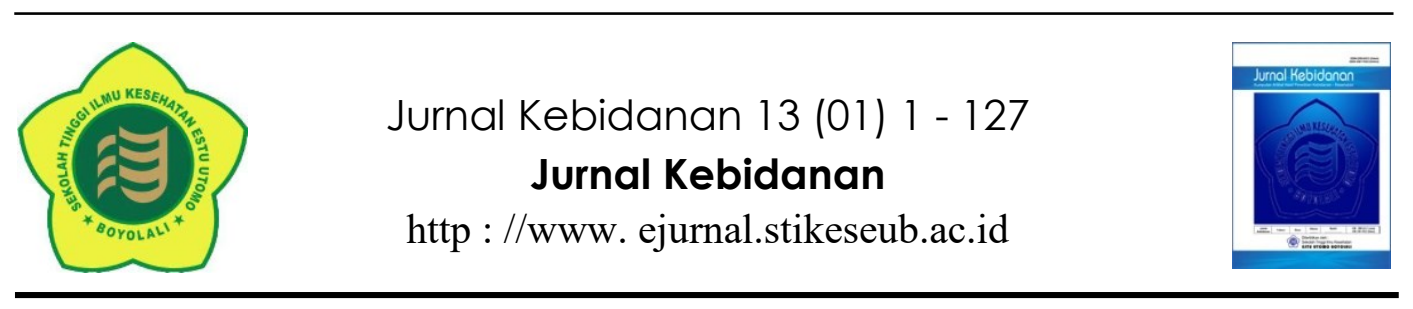

PENGARUH KONSUMSI GREEN TEA TERHADAP NYERI DISMENORE

\title{
PADA REMAJA PUTRI
}

\author{
Muliatul Jannah' ${ }^{1)}$, Prihatin Setianingsih ${ }^{2)}$ \\ 1), 2) Midwifery Program, Medical Faculty, Sultan Agung Islamic University Semarang \\ E-mail : mulitulajannah@unissula.ac.id,pinksetianingsih@gmail.com
}

\begin{abstract}
ABSTRAK
Mengkonsumsi green tea merupakan cara untuk menghilangkan atau menurunkan rasa nyeri yaitu secara non farmakologis tanpa memberikan efek samping. Selain itu mengkonsumsi green tea merupakan cara yang murah serta mudah untuk dilakukan sehingga tidak memerlukan biaya yang mahal untuk menggunakannya.Dismenore memberikan dampak terhadap aktivitas dari remaja, seperti terganggunya aktivitas belajar dan menurunkan konsentrasi karena nyeri yang dirasakan. Konsumsi green tea dapat menimbulkan relaksasi sehingga merangsang hormon endorfin. Hasil studi pendahuluan yang dilakukan di SMAN 1 Negeri Agung Kabupaten Way Kanan berdasarkan dari data absen masing-masing kelas, masih banyak siswi yang absen karena alasan dismenore. Tujuan penelitian diketahuinya pengaruh konsumsi green tea terhadap nyeri dismenore pada remaja putri. Jenis penelitian yang digunakan dalam penelitian ini adalah kuantitatif dengan pendekatan quasi eksperimen dengan rancangan one group pretest-posttest design. Populasi siswi kelas XXII SMAN 1 Negeri Agung Kabupaten Way Kanan yang mengalami dismenore sebanyak 93 siswi, dengan teknik simple random sampling dengan jumlah sampel 30. Analisis data menggunakan uji t-dependent. Hasil penelitian didapatkan rata-rata intensitas nyeri dismenore sebelum konsumsi green tea sebanyak 7,67 dengan standar deviasi sebesar 2,42. Rata-rata intensitas nyeri disminorea sesudah konsumsi green tea sebanyak 4,67 dengan standar deviasi sebesar 1,93. Ada pengaruh konsumsi green tea terhadap nyeri disminorea pada remaja putri di SMAN 1 Negeri Agung Kabupaten Way Kanan Tahun 2018 p-value=0,000. Saran, hasil penelitian dapat dijadikan sebagai informasi dan pengetahuan tambahan bagi remaja putri pada khususnya dalam mengkonsumsi green tea untuk mengurangi rasa nyeri pada dismenore primer.
\end{abstract}

Kata Kunci : Green tea, nyeri dismenore, remaja putri.

THE EFFECT OF GREEN TEA CONSUMPTION ON DYSMINORRHEA PAIN IN YOUNG WOMEN

\section{ABSTRACT}

Consuming green tea is a way to relieve or reduce pain that is non-pharmacological without side effects. In addition, consuming green tea is an inexpensive and easy way to do so that it does not require expensive costs to use it. Dismenorrhea has an impact on the activities of adolescents, such as disruption of learning activities and reducing concentration due to the pain they feel. Consumption of green tea can cause relaxation so that it stimulates endorphins. The results of a preliminary study conducted at SMAN 1 Negeri Agung Way Kanan district based on the absent data for each class, there were still many students who were absent for dysmenorrhea reasons. The research objective was to determine the effect of green tea consumption on dysmenorrhea pain in adolescent girls. The type of research used in this research is quantitative with a quasiexperimental approach with a one group pretest-posttest design. The population of students of class XXII SMAN 1 Negeri Agung Way Kanan district who experienced dysmenorrhea was 93 students, using simple random sampling technique with a sample size of 30 . Data analysis used the t-dependent test. The results showed that the average dysmenorrhea pain intensity before consumption of green tea was 7.67 with a standard deviation of 2.42. The average pain intensity of dysminorrhea after consuming green tea was 4.67 with a standard deviation of 1.93. There is an effect of green tea consumption on dysminorrhea pain in young women at SMAN 1 Negeri Agung Way Kanan Regency in 2018 p-value $=0,000$. Suggestion, the research results can be used as additional information and knowledge for young women, especially in consuming green tea to reduce pain in primary dysmenorrhea.

Keywords : Green Tea, dysmenorrheal pain, adolescent. 


\section{PENDAHULUAN}

Pada umumnya 50-60\% wanita diantaranya memerlukan obat-obatan analgesik untuk mengatasi masalah dismenore ini. Gangguan ini sifatnya subjektif, berat dan intensitasnya sukar dinilai, walaupun frekuensi dismenore cukup tinggi dan penyakit ini sudah lama dikenal namun sampai sekarang patogenesisnya belum dapat dipecahkan dengan memuaskan (Mulastin, 2011). Dismenore memberikan dampak terhadap aktivitas dari remaja, salah satu dampaknya adalah terganggunya aktivitas belajar dan juga mampu menurunkan konsentrasi karena nyeri yang dirasakan. Pada umumnya remaja menginginkan cara yang instan dan praktis serta efek yang diberikan berlangsung cepat (Susanto, 2011). Mengkonsumsi green tea merupakan cara untuk menghilangkan atau menurunkan rasa nyeri yaitu secara non farmakologis tanpa memberikan efek samping. Selain itu mengkonsumsi green tea merupakan cara yang murah serta mudah untuk dilakukan sehingga tidak memerlukan biaya yang mahal untuk menggunakannya. Konsumsi green tea dapat meredakan iskemia dengan menurunkan kontraksi uterus dan melancarkan pembuluh darah sehingga dapat meredakan nyeri dengan mengurangi ketegangan, meningkatkan aliran - aliran darah dan meredakan
Vasokongesti pelvis (Anantaboga, 2012). Konsumsi green tea juga akan menimbulkan rasa relaksasi sehingga dapat merangsang hormon endorphine. Endorphin adalah neuropeptide yang dihasilkan tubuh pada saat relaks/tenang. Endorphin dihasilkan di otak dan susunan syaraf tulang belakang. Hormon ini dapat berfungsi sebagai obat penenang alami yang diproduksi otak yang memberikan rasa nyaman dan meningkatkan kadar endorphin dalam tubuh untuk mengurangi rasa nyeri pada saat dismenore (Anantaboga, 2012).

Hasil studi pendahuluan yang dilakukan di SMAN 1 Negeri Agung Kabupaten Way Kanan berdasarkan dari data absen masing-masing kelas, masih banyak siswi yang absen karena alasan dismenore. Hasil wawancara dari 10 siswi $(10,8 \%)$ dari 93 siswi didapatkan bahwa delapan dari siswi tersebut mengalami nyeri perut setiap kali menstruasi dan dua orang kadangkadang mengalaminya. Dua orang mengatakan bahwa cara yang digunakan untuk mengurangi rasa nyeri itu dengan minum minuman yang tersedia di toko yang berfungsi menghilangkan nyeri haid, tiga orang mengatakan cara mengatasinya dengan minum obat penghilang nyeri,lima orang dengan istirahat dan jongkok serta pernah mengkonsumsi green tea juga dapat 
mengurangi nyeri disminore yang dapat mengganggu aktivitas belajar siswi.

\section{METODE}

Jenis penelitian ini adalah kuantitatif. Desain penelitian yang digunakan adalah one group pretestpostest dimana pada penelitian ini sampel diobservasi terlebih dahulu sebelum (pretest) diberi perlakuan kemudian setelah (postest) diberikan perlakuan dan sampel tersebut di observasi kembali (Notoatmodjo, 2012). Green tea bisa dikonsumsi dalam satu hari 2 kali minum saat ingin berativitas dan sore hari. Populasi dalam penelitian ini adalah siswi kelas X-XII SMAN 1 Negeri Agung Kabupaten Way Kanan yang mengalami dismenore sebanyak 93 siswi. Jumlah sampel dalam penelitian ini sebanyak 30 orang. Teknik pengambilan sample pada penelitihan ini menggunakan simple random sampling.

\section{HASIL DAN PEMBAHASAN}

\section{Analisis Univariat}

a. Intensitas nyeri disminorea sebelum konsumsi green tea

Tabel 1.

Intensitas Nyeri Disminorea Sebelum Konsumsi Green $t$

\begin{tabular}{cccccc}
\hline Intensitas Nyeri & $\mathrm{N}$ & Minimum & Maximum & Mean & Std. Deviation \\
\hline Sebelum & 30 & 4,00 & 10,00 & 7,6688 & 2,42074 \\
\hline
\end{tabular}

Berdasarkan tabel di atas, maka diketahui bahwa rata-rata (mean) Intensitas nyeri disminorea sebelum konsumsi green tea sebesar 7,6688.

Tabel 2.

Intensitas Nyeri Disminorea Sesudah Konsumsi Green $t$

\begin{tabular}{rllllc}
\hline Intensitas Nyeri & $\mathrm{N}$ & Minimum & Maximum & Mean & Std. Deviation \\
\hline Sesudah & 30 & 2,00 & 8,00 & 4,6667 & 1,92959
\end{tabular}

Berdasarkan tabel di atas, maka diketahui bahwa rata-rata (mean) Intensitas nyeri disminorea sesudah konsumsi green tea sebesar 4,6667.

\section{Analisis Bivariat}

Analisis bivariat ini menggunakan uji $\mathrm{t}$ dependen dengan hasil sebagai berikut:

Tabel 3.

Pengaruh Konsumsi Green $t$

\begin{tabular}{ccccccc}
\hline Intensitas Nyeri & $\mathrm{N}$ & Minimum & Maximum & Mean & $\begin{array}{l}\text { Standar } \\
\text { Deviasi }\end{array}$ & $\mathrm{p}$-Value \\
\hline Sebelum & 30 & 4,00 & 10,00 & 7,6688 & 2,42074 & 0,000 \\
\hline Sesudah & 30 & 2,00 & 8,00 & 4,6667 & 1,92959 & \\
\hline
\end{tabular}


Berdasarkan tabel di atas diketahui bahwa hasil pengujian dengan uji $\mathrm{t}$ dependent diperoleh $p$-value $=$ 0,000 yang berarti ada pengaruh konsumsi green tea terhadap nyeri disminorea pada remaja putri di SMAN 1 Negeri Agung Kabupaten Way Kanan Tahun 2018.

Berdasarkan hasil penelitian, diketahui rata-rata (mean) intensitas nyeri disminorea sebelum konsumsi green tea pada remaja putri di SMAN 1 Negeri Agung Kabupaten Way Kanan Tahun 2018 sebanyak 7,6688 dengan standar deviasi sebesar 2,42074. Sedangkan rata-rata (mean) Intensitas nyeri disminorea sesudah konsumsi green tea pada remaja putri di SMAN 1 Negeri Agung Kabupaten Way Kanan Tahun 2018 sebesar 4,6667 dengan standar deviasi sebesar 1,92959. Hasil pengujian dengan uji $t$ dependent diperoleh $p$-value $=0,000$ yang berarti ada pengaruh konsumsi green tea terhadap nyeri disminorea pada remaja putri di SMAN 1 Negeri Agung Kabupaten Way Kanan Tahun 2018. Menurut Benson dan Pernoll (2009) desminore merupakan kejang perut bagian bawah yang hebat dan sangat sakit tepat sebelum atau selama menstruasi gejala-gejala lain dapat berupa berkeringat, sakit kepala, mual, muntah, diaredan tremor. Desminore mungkin merupakan keluhan pasien ginekologi yang umum terjadi, menyerang $75 \%$ dari seluruh wanita. Dari semua wanita yang terkena, 50\% melaporkan gejala gejala ringan (yaitu tidak ada gejala sistemik, obat-obatan jarang diperlukan dan pekerjaan jarang terganggu), $30 \%$ mengalami gejala sedang (yaitu ada beberapa gejala sistemik, memerlukan obat, pekerjaan cukup terganggu) dan $20 \%$ mempunyai gejala berat (yaitu banyak gejala, respon terhadap obat buruk dan pekerjaan terhambat).

Tanda-tanda nyeri menstruasi (dismenore) adalah nyeri pada perut bagian bawah didaerah umbilikus dan supra pubik perut. Halini biasanya juga sering dirasakan diperut bagian kanan dan kiri yang dapat menyebar ke paha, punggung bagian bawah sampai ketungkai. Nyeri atau kram yang dirasa akan hilang timbul atau nyeri tumpul yang terus menerus ada. Nyeri biasanya mulai timbul sesaat sebelum atau selama menstruasi, serta mencapa ipuncaknya dalam waktu 24 jam dan setelah 2 hari akan menghilang. Kadangkadang dismenore juga sering disertai oleh rasa sakit kepala, pusing, sembelit, diare, pingsan, kelelahan, sering berkemih, mual sampai terjadi muntah (Anurogo dan Wulandari, 2011).

Nyeri haid ini adalah normal, namun dapatberlebihan apabila dipengaruhi oleh faktor fisik dan psikis 
seperti stress, shock, penyempitan pembuluh darah, penyakit yang menahun, kurang darah, kondisi tubuh yang menurun, atau pengaruh hormon prostaglandine. Gejala ini tidak membahayakan kesehatan. Nyeri haid sekunder biasanya baru muncul kemudian, yaitu jika ada penyakit yang datang kemudian. Penyebabnya adalah kelainan atau penyakit seperti infeksi rahim, kista atau polip, tumor sekitar kandungan, atau bisa karena kelainan kedudukan rahim yang menetap. Ada juga yang disebut dengan endometriosis, yaitu kelainan letak lapisan dinding rahim yang menyebar keluar rahim, sehingga apabila menjelang menstruasi, pada saat lapisan dinding rahim menebal, akan dirasakan nyeri atau sakit yang luar biasa. Selain itu, endometriosis ini juga bisa mengganggu kesuburan (Anurogo dan Wulandari, 2011).

Hasil penelitian ini sejalan dengan hasil penelitian Hasil penelitian Fitriana (2016) tentang pengaruh konsumsi green tea terhadap nyeri disminorea pada remaja putri di SMA Persada Bandar Lampung Tahun 2016. Hasil penelitian didapatkan rata- rata (mean) intensitas nyeri disminorea sebelum konsumsi green tea pada remaja putri di SMA Persada Bandar Lampung Tahun 2016 sebanyak 8,9160 dengan standar deviasi sebesar 2,00056.
Intensitas nyeri disminorea sesudah konsumsi green tea pada remaja putri di SMA Persada Bandar Lampung Tahun 2016 sebanyak 5,8640 dengan standar deviasi sebesar 1,64845. Ada pengaruh konsumsi green tea terhadap nyeri disminorea pada remaja putri di SMA Persada Bandar Lampung tahun $2016 p$-value $=0,000$.

Selain itu sejalan juga dengan hasil penelitian Sari (2015) tentang Pengaruh Aroma Terapi Jasmine Terhadap Penurunan Skala Nyeri Pada Remaja Putri Yang Mengalami Dismenore Di Sman 2 Pontianak Tahun2015. Hasil sebelum dilakukan aroma terapi jasmine didapatkan nyeri sedang $62,5 \%$ dan nyeri berat $37,5 \%$. Setelah dilakukan aroma terapi jasmine didapatkan tidak nyeri $31,2 \%$, nyeri ringan $56,2 \%$ dan nyeri sedang $12,5 \%$. Pada uji t-tes paired didapatkan hasil bahwa nilai $\mathrm{p}=0,000$, dimana $\mathrm{p}<0,05$.

Berdasarkan uraian di atas maka menurut peneliti konsumsi green tea juga akan menimbulkan rasa relaksasi sehingga dapat merangsang hormon endorphine. Endorphin adalah neuropeptide yang dihasilkan tubuh pada saat relaks/tenang. Endorfin dihasilkan di otak dan susunan syaraf tulang belakang. Hormon ini dapat berfungsi sebagai obat penenang alami yang diproduksi otak yang memberikan 
rasa nyaman dan meningkatkan kadar endorphin dalam tubuh untuk mengurangi rasa nyeri pada saat dismenore.

\section{PENUTUP}

Berdasarkan hasil penelitian dan pembahasan, maka dapat disimpulkan bahwa rata-rata intensitas nyeri dismenore sebelum konsumsi green tea pada remaja putri di SMAN 1 Negeri Agung Kabupaten Way Kanan Tahun 2018 sebanyak 7,67 dengan standar deviasi sebesar 2,42. Rata-rata intensitas nyeri disminorea sesudah konsumsi green tea pada remaja putri di SMAN 1 Negeri Agung Kabupaten Way Kanan Tahun 2018 sebanyak 4,67 dengan standar deviasi sebesar 1,93. Ada pengaruh konsumsi green tea terhadap nyeri disminorea pada remaja putri di SMAN 1 Negeri Agung Kabupaten Way Kanan Tahun 2018 p-value $=0,000$.

Hasil penelitian ini dapat
dijadikan sebagai informasi dan
pengetahuan tambahan bagi remaja putri
pada khususnya dalam mengkonsumsi
green tea untuk mengurangi rasa nyeri
pada dismenore primer. Pihak sekolah
dapat bekerjasama dengan puskesmas
terkait dalam penanganan nyeri pada
dismenore dengan menggunakan
pengobatan komplementer yaitu dengan

